\title{
latrogenic biological fracture of the cervical spine during gradual halo traction for kyphotic deformity correction: case report
}

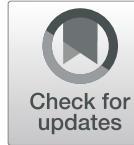

\author{
Austin Samuel Laifun Lim, Azizul Akram Bin Sali and Jason Pui Yin Cheung * (1)
}

\begin{abstract}
Background: Severe kyphotic deformities carry high risk for neurological injuries as osteotomies are often required for correction. Surgeons often utilize a staged approach for dealing with these conditions starting with a period of halo traction to stretch tight soft tissues and partially correct the deformity, followed by surgery. Halo traction is a relatively safe procedure and complications are uncommon. We report a unique case of iatrogenic fracture of the cervical spine during gradual halo traction for deformity correction of a severe cervical kyphosis.
\end{abstract}

Case presentation: An 80-year-old female with previous cervical spine tuberculosis infection and C5-C6 anterior spinal fusion developed severe cervical kyphosis of 64 from C2-C6 and neck pain requiring deformity correction surgery. Gradual increase in traction weight was applied, aiming for a maximum traction weight of 45 pounds or half body weight. During the 1st stage halo-gravity traction, sudden neck pain and a loud cracking sound was witnessed during increase of the traction weight to 14 pounds. Imaging revealed a fracture through the C4 and reduction in kyphosis deformity to $11^{\circ}$ from C2-C6. There was no neurological deficit. No further traction was applied and the patient underwent an in-situ occipital to T3 fusion without osteotomies. At 3-year follow-up, the patient was symptom-free and radiographs showed solid fusion and maintenance of alignment.

Conclusions: latrogenic fracture may occur with halo traction. Elderly patients with osteoporotic and diseased bone should be closely monitored during the treatment. A fracture without complications was a fortunate complication as the patient was able to avoid any high-risk osteotomies for deformity correction.

Level of evidence: IV

Keywords: Cervical kyphosis, Halo traction, latrogenic fracture, Deformity correction, Osteotomy, Case report

\section{Background}

Kyphotic deformities of the cervical spine are rare but can cause debilitating disease due to axial neck pain and cord compression. Surgical intervention can correct the kyphotic deformity, restore lordosis and decompress the cord. One technique to achieve this

\footnotetext{
*Correspondence: cheungjp@hku.hk

Department of Orthopaedics and Traumatology, The University of Hong Kong, Professorial Block, 5th Floor, 102 Pokfulam Road, Pokfulam, Hong Kong SAR, China
}

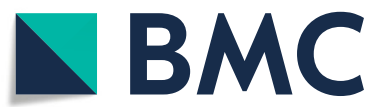

(c) The Author(s). 2020 Open Access This article is licensed under a Creative Commons Attribution 4.0 International License, which permits use, sharing, adaptation, distribution and reproduction in any medium or format, as long as you give appropriate credit to the original author(s) and the source, provide a link to the Creative Commons licence, and indicate if changes were made. The images or other third party material in this article are included in the article's Creative Commons licence, unless indicated otherwise in a credit line to the material. If material is not included in the article's Creative Commons licence and your intended use is not permitted by statutory regulation or exceeds the permitted use, you will need to obtain permission directly from the copyright holder. To view a copy of this licence, visit http://creativecommons.org/licenses/by/4.0/. The Creative Commons Public Domain Dedication waiver (http//creativecommons.org/publicdomain/zero/1.0/) applies to the data made available in this article, unless otherwise stated in a credit line to the data. nically demanding with high is One study suggests an incidence of $13 \%$ for neurologic injury [1]. To minimize surgical risk, staged procedure with halo gravity traction followed by osteotomy is often adopted. The period of traction can stretch any tight neck muscles and partially correct the deformity. Less aggressive osteotomies can be performed at the second stage to reduce risk of complications. Comparatively, halo traction has less risk 

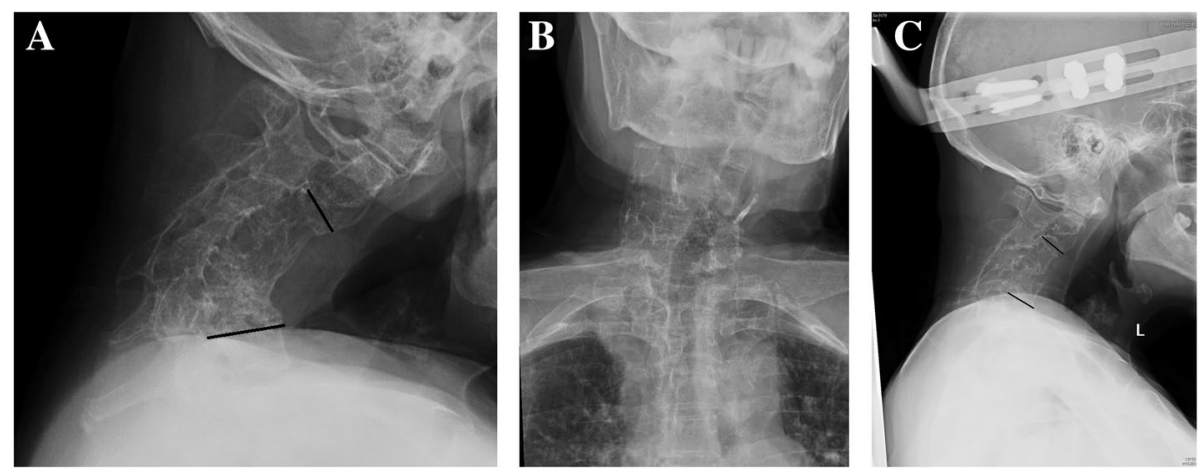

Fig. 1 a Lateral cervical X-ray shows severe kyphotic angle of $64^{\circ}$ before traction; $\mathbf{b}$ anteroposterior cervical X-ray shows a tilt to the left. $\mathbf{c}$ After the iatrogenic fracture at $C 4$, the kyphotic angle improved to $11.2^{\circ}$

with mainly pin loosening (36\%) and pin site infections $(20 \%)$ as the predominant complications [2]. This is a case of an iatrogenic fracture of the cervical vertebrae while under halo gravity traction with an unintended result of correcting the cervical kyphosis to an alignment satisfactory for in-situ fusion without osteotomy.

\section{Case report}

An 80 years old female with previous cervical spine tuberculosis infection, and underwent C5-C6 anterior spinal fusion in 1994, presented with severe cervical kyphosis. She also had comorbidities of dermatomyositis on azathioprine for more than 20 years. She had severe neck pain, and easy fatigue due to difficulties in maintaining a horizontal gaze. She did not have any complaints of hand clumsiness, paresthesia or radicular pain, and had intact hand function. However, examination identified bilateral hand weakness with motor power of $4 / 5$, positive reverse supinator jerks and Hoffman's sign. Cervical spine x-ray (Fig. 1a) revealed severe kyphotic deformity of $64^{\circ}$ from C2-C6 with apex of the deformity at C5. There was a fused C4-C6 with osteoporotic bone. The head was also tilted to the left (Fig. 1b).

A two-stage procedure involving halo-gravity traction followed by combined anterior and posterior instrumented fusion and multiple posterior column osteotomies was planned for her deformity correction. Since she weighed 110 pounds, maximum traction weight of 45 pounds was planned. Five pounds of traction was added after halo insertion followed by daily gradual increments of two pounds. The patient tolerated traction with no pin loosening nor cranial nerve palsies. At 14 pounds of traction weight, the patient complained of sudden neck pain and a loud cracking sound. X-ray taken immediately (Fig. 1c) with CT scan (Fig. 2). A fracture through the previously fused $\mathrm{C} 4$ vertebral body was found. There was no neurological compromise but the neck posture markedly improved. A reduction in kyphotic deformity was observed with good horizontal gaze. The kyphotic angle was measured to be $11^{\circ}$ from $\mathrm{C} 2-\mathrm{C} 6$. No further traction was applied and she then underwent a combined anterior and posterior in-situ fusion without any osteotomies due to the satisfactory cervical

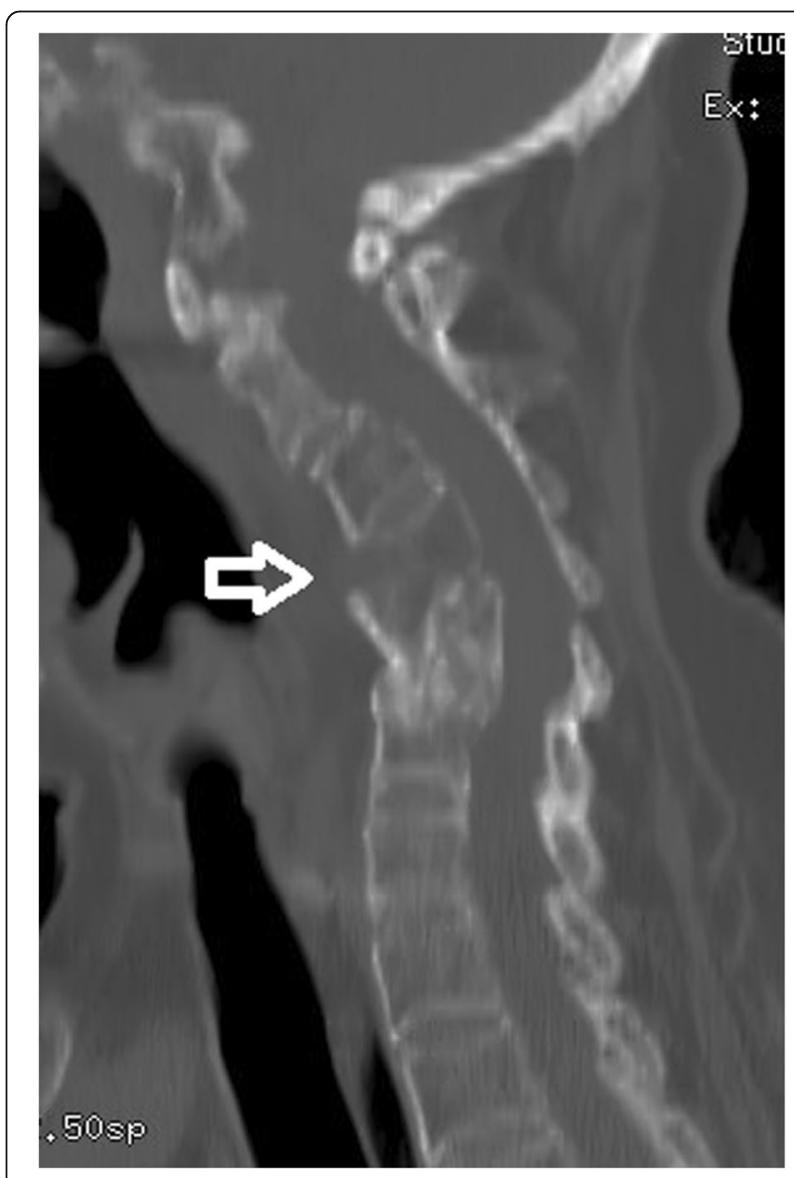

Fig. 2 Sagittal $C T$ scan after fracture with the white arrow pointing at the fracture line 



Fig. 3 a Lateral cervical X-ray taken immediately postop showing a kyphotic angle of $15.4^{\circ}$ from C2-6; b The kyphotic angle maintained at threeyears after the anterior and posterior in-situ fusion and instrumentation with solid fusion; c The anteroposterior alignment was improved

alignment. An anterior cage was placed at C4-C5 with posterior iliac crest autograft. Posterior instrumented fusion was performed from occiput to T3 using an occiput plate with lateral mass screws from C3-C6 and pedicle screws from T1-T3 (Fig. 3a). The patient was well perioperatively and used a cervical collar for 2 weeks. She was then transferred to a rehabilitation centre on postoperative day 9 and discharged 2 weeks after surgery. At 3-years follow-up, she was symptomfree with solid fusion and maintenance of kyphotic correction (Fig. 3b) and head tilt (Fig. 3c).

\section{Discussion and conclusions}

Surgical management of severe kyphosis usually requires multiple osteotomies. These procedures carry high complication rates (26.9-87.5\%) with a mortality rate of $2.6 \%$ [3]. Complications include epidural bleeding, neurological impingement, C8 nerve palsy, non-union and infections [4], dysphagia and need for tracheostomy/intubation $[5,6]$. Complications are more common for elderly patients, American Society of Anesthesiologists (ASA) classification of III or IV, and increased operative times [7]. Among these complications, cardiopulmonary dysfunction is the most common cause for mortality [8]. Patients undergoing subaxial spine osteotomies have more complications than patients undergoing higher thoracic osteotomies [1]. With the risks accompanying cervical osteotomy, one strategy to minimize this is to have the patient undergo gradual traction before the deformity correction surgery. Xiaojin et al reported an initial improvement of kyphotic deformity by approximately $20^{\circ}$ with this method [9].

Complications with halo-gravity traction are uncommon but neurological deterioration including brachial plexus injuries and cranial nerve palsies may occur $[10,11]$. Although there are a few reported cases of iatrogenic fracture during surgery for ankylosing spondylitis [12], this is the first report of an iatrogenic fracture to the cervical spine while on halogravity traction. Our patient has many risk factors leading to the iatrogenic cervical fracture including advanced age with a previously diseased bone and infection. The poor bone quality and tight soft tissues are important factors associated with the iatrogenic fracture. This is evidenced by the fracture occurring despite slow increase in traction at a relatively light weight. Nevertheless, it was a fortuitous complication as the patient did not develop any neurological compromise and avoided the high-risk osteotomies. Insitu fusion with an anterior cage was performed to encourage fusion across the anterior column defect at C4-C5.

This case serves to highlight that vertebral body fractures can occur during traction the cervical spine. Vigilant monitoring should be done for elderly patients with osteoporotic bone and with history of prior infection undergoing halo gravity traction.

\section{Abbreviations}

ASA: American society of anesthesiologists

\section{Acknowledgements}

Nil.

\section{Declaration}

Written informed consent was obtained from the patient for publication of this case report and any accompanying images. A copy of the written consent is available for review by the Editor of this journal.

\section{Authors' contributions}

ASLL contributed to data acquisition, analysis and interpretation and drafted the work. AABS contributed to data acquisition, analysis and interpretation and drafted the work. JPYC contributed to the study design, data acquisition, analysis and interpretation, and revised the manuscript. All authors approved the submitted version and have agreed both to be personally accountable for their own contributions and to ensure that questions related to the accuracy or integrity of any part of the work, even ones in which the author was not personally involved, are appropriately investigated, resolved, and the resolution documented in the literature. 


\section{Funding}

Nil.

\section{Availability of data and materials}

Not applicable as this is a case report.

\section{Ethics approval and consent to participate}

Ethics approval was obtained from the institutional review board of the University of Hong Kong/Hospital Authority Hong Kong West Cluster (UW

15-102) and written informed consent was obtained.

\section{Competing interests}

There are no financial or non-financial competing interests. JPYC is an associate editor of BMC Musculoskeletal Disorders.

Received: 14 April 2020 Accepted: 14 May 2020

Published online: 21 May 2020

\section{References}

1. Theologis AA, Burch S. Safety and efficacy of reconstruction of complex cervical spine pathology using pedicle screws inserted with stealth navigation and 3D image-guided (O-arm) technology. Spine (Phila Pa 1976). 2015;40(18):1397-406.

2. Garfin SR, Botte MJ, Waters RL, Nickel VL. Complications in the use of the halo fixation device. J Bone Joint Surg Am. 1986;68(3):320-5.

3. Etame AB, Than KD, Wang AC, La Marca F, Park P. Surgical management of symptomatic cervical or cervicothoracic kyphosis due to ankylosing spondylitis. Spine (Phila Pa 1976). 2008;33(16):E559-64.

4. Kose KC, Bozduman O, Yenigul AE, Igrek S. Spinal osteotomies: indications, limits and pitfalls. EFORT Open Rev. 2017;2(3):73-82.

5. Koller H, Meier O, Zenner J, Mayer M, Hitzl W. In vivo analysis of cervical kinematics after implantation of a minimally constrained cervical artificial disc replacement. Eur Spine J. 2013;22(4):747-58.

6. Mummaneni PV, Dhall SS, Rodts GE, Haid RW. Circumferential fusion for cervical kyphotic deformity. J Neurosurg Spine. 2008;9(6):515-21.

7. DePasse JM, Durand W, Daniels AH. Predictors of nonneurologic complications and increased length of stay after cervical spine osteotomy. World Neurosurg. 2018;118:e727-e30.

8. Smith JS, Shaffrey Cl, Kim HJ, Passias P, Protopsaltis T, Lafage R, et al. Prospective multicenter assessment of all-cause mortality following surgery for adult cervical deformity. Neurosurgery. 2018;83(6):1277-85.

9. Li X, Zeng L, Li X, Chen X, Ke C. Preoperative halo-gravity traction for severe thoracic Kyphoscoliosis patients from Tibet: radiographic correction, pulmonary function improvement, nursing, and complications. Med Sci Monit. 2017;23:4021-7.

10. Qian BP, Qiu Y, Wang B. Brachial plexus palsy associated with halo traction before posterior correction in severe scoliosis. Stud Health Technol Inform. 2006;123:538-42.

11. Wilkins C, MacEwen GD. Cranial nerve injury from halo traction. Clin Orthop Relat Res. 1977;126:106-10.

12. Ruf M, Rehm S, Poeckler-Schoeniger C, Merk HR, Harms J. latrogenic fractures in ankylosing spondylitis--a report of two cases. Eur Spine J. 2006; 15(1):100-4

\section{Publisher's Note}

Springer Nature remains neutral with regard to jurisdictional claims in published maps and institutional affiliations. 